\title{
Polycyclic aromatic hydrocarbons (PAHs) in surface sediments from the largest deep plateau lake in China: Occurrence, sources and biological risk
}

\author{
Yang-Guang $\mathrm{Gu}^{\mathrm{a}}{ }^{\mathrm{d}, \mathrm{e}} *$, Hua-Bing $\mathrm{Li}^{\mathrm{b}}$, Hui-Bin $\mathrm{Lu}^{\mathrm{b}, \mathrm{c}}$
}

\section{Abstract}

The unprecedented rate at which economy, urbanization and industrialization have occurred in China in the last few decades has resulted in environmental pollution in China. Polycyclic aromatic hydrocarbons (PAHs) are of great concern because of their persistence, long-range transport properties, and health risk as potential carcinogens and mutagens. Plateau lakes are special ecosystem and located in remote western China. To our knowledge, studies on PAHs in sediments of plateau deep lakes in China are scarce. Therefore, PAHs in surface sediments from Fuxian Lake, the largest deep plateau lake in China, were investigated. The total PAH concentrations ranged from 83.2 to 261.7 , with a mean concentration of $143.3 \mathrm{ng} / \mathrm{g}$. Four-ring PAHs (39.1-73.9\%) were most abundant in all samples. The composition of PAHs was characterized by high molecular weight PAHs, and FA and PHE were the dominant 
constituents. A correlation analysis revealed that TOC was positively significantly correlated with total PAHs, while percentages of grain size fraction were poorly correlated with total PAHs. PAH diagnostic ratios demonstrated that PAHs mainly originated from biomass, coal, and petroleum combustion. Taking as a whole, surface sediments of Fuxian Lake had a 9\% incidence of adverse biological effects based on the mean effects range-median quotient.

Keywords: PAHs; Sediment; Sources; Biological risk; Fuxian Lake

\section{Introduction}

Sediments are effective sinks for pollutants such as polycyclic aromatic hydrocarbons (PAHs) in aquatic ecosystems, but also act as a source of pollutants (White and others 2005; Guo and others 2010; Lu and others 2012; Gregg and others 2015). PAHs are a large group of organic compounds with two or more fused aromatic rings, and they primarily originate from the incomplete combustion of carbonaceous materials (Boström and others 2002; Martins and others 2010; Shen and others 2013; Gu and others 2016). PAHs are of great concern because of their persistence, long-range transport properties, and health risk as potential carcinogens and mutagens (Perera 1997; Zhang and others 2012; Gu and others 2013).

Freshwater deep plateau lakes are special ecosystems. Inputs of PAHs into lakes are generally predominated by atmospheric deposition rather than direct intake (Yang and others 2016). Few studies have been conducted to investigate concentrations and 
sedimentary record of PAHs in plateau lakes in China (Guo and others 2010; Zhao and others 2014; Yang and others 2016), but studies on PAHs in sediments of deep plateau lakes in China and the resulting biological risks are scarce.

Fuxian Lake, situated in the central part of Yunnan Province on the Yunnan-Guizhou Plateau in Southwest China (Fig.1), covers an area of $212 \mathrm{~km} 2$, with a maximum depth of $155 \mathrm{~m}$, and water residence time of 167 years (Liu and others 2008; Zhao and others 2012; Zhang and others 2015). As the largest deep freshwater lake in China, it has been seriously influenced by anthropogenic activities such as industrial and agricultural development, deforestation, and tourism since the 1980s (Liu and others 2008; Zeng and Wu 2009; Zhang and others 2015). Previous studies show that anthropogenic activities in the areas, related to increasing nutrient inputs, have resulted in the deterioration of the aquatic ecosystem and environment over the past years (Liu and others 2008; Zeng and Wu 2009). It is therefore necessary to evaluate pollutants, such as PAH levels, in aquatic sediments. Therefore, the present study was designed to (1) determine PAH concentrations in surface sediments of Fuxian Lake, and (2) identify potential sources and evaluate biological risks of PAHs in this region.

2. Materials and methods

\subsection{Sample collection}

Sediment sampling was undertaken along a transect down the long axis of the lake, as proposed by Mudroch and Azcue (1995). The water depth contour of Fuxian 
Lake has been described in detail in previous studies (Liu and others 2008; Zhang and others 2015). Along the transect, eight sites were selected and located for our study. Surface sediment was obtained using a stainless steel Peterson grab sampler in August 2015 (Fig. 1). At each site, two sets of samples were carefully taken from a sediment depth of $0-3 \mathrm{~cm}$ with a polyethylene spatula and placed in self-sealing polyethylene bags. Prior to analysis, one set of samples was stored at $-4^{\circ} \mathrm{C}$ and the other at $-20^{\circ} \mathrm{C}$. Samples at $-4^{\circ} \mathrm{C}$ were used for grain size analysis; those kept at $-20^{\circ} \mathrm{C}$ were freeze-dried to constant weight, homogenized using an agate mortar and pestle, sieved through a 200 mesh stainless steel mesh $(<74 \mu \mathrm{m})$, and stored in a glass bottle at -4 ${ }^{\mathrm{o}} \mathrm{C}$ in until analysis of total organic carbon (TOC) and PAHs. 

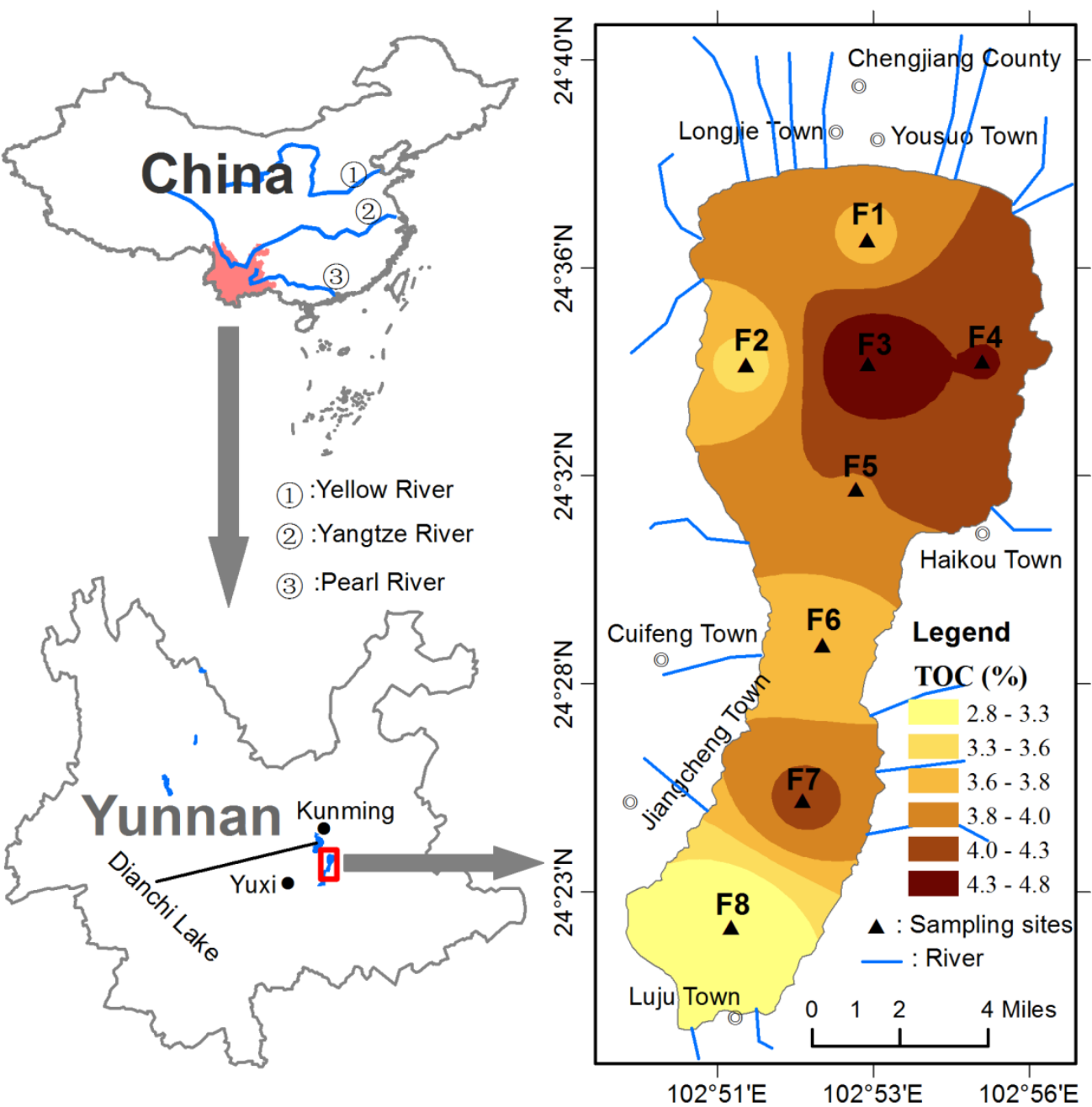

Fig. 1. Map showing the sampling sites and distribution of total organic carbon (TOC) in surface sediments from Fuxian Lake, Southwest China.

\subsection{Analytical methods}

The pre-treatment procedures for grain size analysis were conducted in accordance with the Chinese National Standards (GB/T12763.8-2007). Sample granulometry was analyzed using a Malvern Mastersizer 2000 laser, diffractometer capable of analyzing particle sizes between 0.02 and $2,000 \mu \mathrm{m}$. The percentages of grain size were divided into three groups: $<4 \mu \mathrm{m}$ (clay), $4-63 \mu \mathrm{m}$ (silt), and $>63 \mu \mathrm{m}$ (sand). Organic matter content was determined by loss on ignition (LOI) at $550^{\circ} \mathrm{C}$ for $4 \mathrm{~h}$ (Heiri and others 2001). Subsequently, total organic carbon (TOC) content was 
calculated by using a correction factor of 1.72 (De Jonge and others 2012). Pre-treatments and measurements of 16 PAHs in surface sediments were performed as described in our previous study (Gu and others 2013).

For quality assurance and control, surrogate standards were added to all sedimentary samples prior to extraction to quantify the procedural recoveries. PAHs were quantified using the internal calibration method based on five-point calibration curves for individual compounds. The surrogate recoveries (mean \pm standard deviation) were $76 . \pm 7.8,90.5 \pm 8.7,101.4 \pm 9.5 \%$ for acenaphthene- $d_{10}$, chrysene- $d_{12}$, perylene- $d_{12}$ and phenanthrene- $d_{10}$, respectively. We used Nation Institute of Standard and Technology (NIST) standard material (SRM 1941) and quantified PAHs applying the internal calibration method. Recoveries of 16 PAHs in the NIST 1941 sample varied from 82.3 to $104.6 \%$ of the certified values. Blank samples contained no detectable amount of the targeted PAHs, and the relative percent analysis difference of paired duplicate samples was less than $12 \%(n=12)$. The PAHs and standard materials were analyzed using a chromatography-mass spectrometer (Agilent 7890 series gas chromatograph/5975C mass spectrometer, Agilent Technologies, USA).

The instrument detection limits varied from 0.2 to $2 \mathrm{ng} / \mathrm{g}$. The 16 US EPA priority PAHs analyzed were: naphthalene (NA), acenaphthylene (ACL), acenaphthene (AC), fluorene (FL), phenanthrene (PHE), anthracene (AN), fluoranthene (FA), pyrene (PY), benzo(a)anthracene (BaA), chrysene (CHR), benzo(b)fluoranthene (BbFA), benzo(k)gluoranthene (BkFA), benzo(a)pyrene $(\mathrm{BaP})$, Indeno(1,2,3-c,d)pyrene (IP), dibenzo(a.h)anthracene $\quad$ (DBahA) and 
benzo(g,h,i)perylene (BghiP).

\section{Results and discussion}

\subsection{Sediment characteristics}

Total organic carbon (TOC) contents varied between 2.8 and $4.8 \%$ of the dry sediment weight, with an average of $3.8 \%$ (Fig. 1). The relative higher TOC contents (> 4.3\%) were all recorded at sites F3 and F4 in the northeastern part of Fuxian Lake (Fig. 1). The ternary diagram in Fig. S1 categorizes the sediments of Fuxian Lake using the system of Shepard (1954), revealing clear spatial patterns. Apart from sampling sites F2, F6, and F8, which were dominated by clayey silt, the studied surface sediments of Fuxian Lake were predominated by silty clay.

\subsection{PAHs levels in sediments}

Surface sediments can reflect the current contamination status (Gu and others 2013). Table 1 shows the concentrations of the 16 US EPA priority PAHs in surface sediments from Fuxian Lake. Total PAH concentrations ( $\mathrm{PAHs}$ ) from all sediment samples varied from 83.2 to 261.7 , with a mean concentration of $143.3 \mathrm{ng} / \mathrm{g}$. Thirteen individual PAHs were found at all stations, with the exception of BbFA, IP and DBahA. Bap, the most carcinogenic among all PAHs compounds (San José and others 2013), was detected at all stations (0.8-4.4 ng/g, mean $2.3 \mathrm{ng} / \mathrm{g})$. FA was the most abundant PAH with concentrations between 11.4 and $91.9 \mathrm{ng} / \mathrm{g}$ (mean $32.9 \mathrm{ng} / \mathrm{g}$ ), 
135

136

137

138

139

140

141

142

143

144

145

146

147

followed by PHE (19.5-32.2 ng/g, mean 25.1), NA (0.5-56.2 ng/g, mean $22.9 \mathrm{ng} / \mathrm{g})$, and PY (8.5-56.9 ng/g, mean $21.7 \mathrm{ng} / \mathrm{g})$. These four groups contributed more than $71.6 \%$ to the total PAHs concentration. The highest and relatively higher concentrations of some sites in northeast Fuxian Lake may be attributed to the cumulative effects of water discharge from urban runoffs, sewage discharges, oil spills from boats, and petroleum combustion (Fig. 2a). In addition, the TOC might have facilitated PAH concentrations (Fig.1).

Fig. 2b shows a comparison of PAH concentrations in surface sediments collected of different plain lakes. Average total PAH concentrations in surface sediments of Fuxian Lake were significantly lower than those in sediments from Chaohu Lake, Dianchi Lake and Taihu Lake, but only slightly lower than concentrations in Poyang Lake and Baiyangdian Lake. 


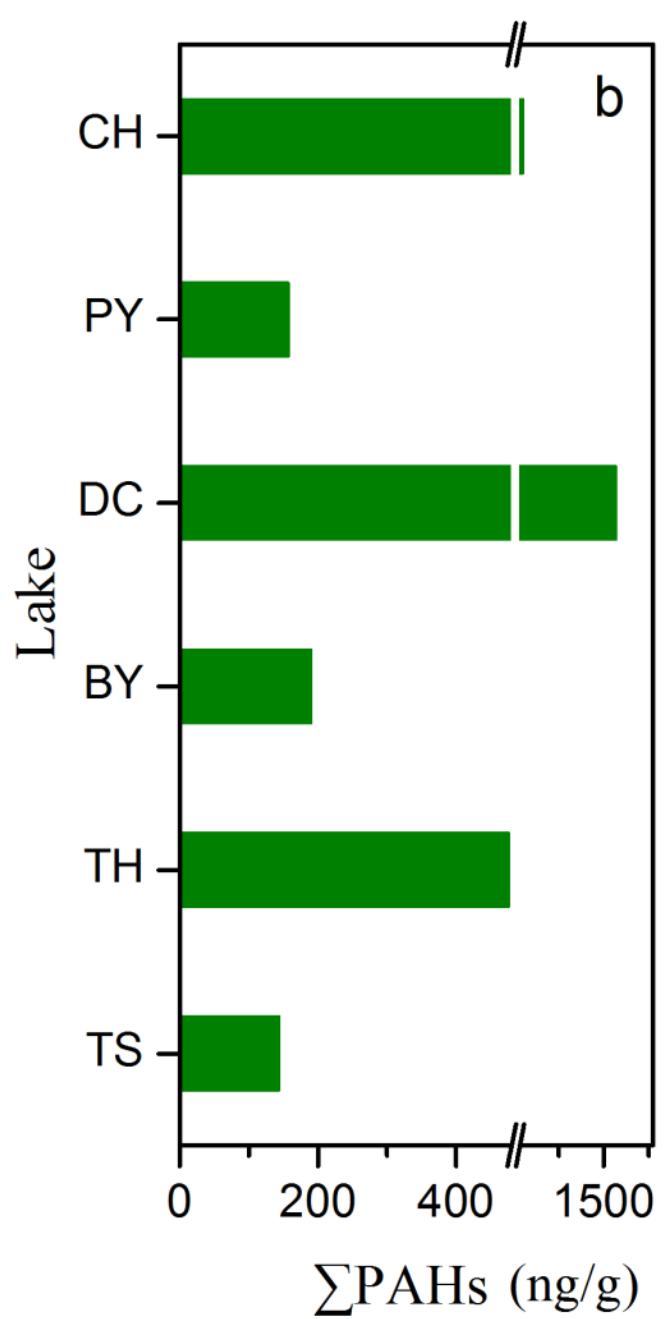

Fig. 2. Spatial distribution of PAHs in surface sediments from Fuxian Lake (a) and mean concentrations of PAHs in surface sediments soils different Chinese lakes (b). CH: Chaohu Lake (Wang and others 2011); PY: Poyang Lake (Lu and others 2012); DC: Dianchi Lake (Zhao and others 2014); BY: Baiyangdian Lake (Hu and others 2010); TH: Taihu Lake (Zhang and others 2012); TS: Fuxian Lake (This study). 
161 Table 1 Concentrations of PAHs in surface sediment from Fuxian Lake (ng/g, dry weight).

\begin{tabular}{|c|c|c|c|c|c|c|c|c|c|c|}
\hline PAHs & $\mathrm{F} 1$ & $\mathrm{~F} 2$ & F3 & F4 & F5 & F6 & F7 & F8 & ERL & ERM \\
\hline NA & 56.2 & 6.5 & 1.1 & 50.6 & 7.0 & 5.4 & 55.9 & 0.5 & 160 & 2100 \\
\hline ACL & 0.4 & 0.3 & 0.9 & 0.5 & 0.4 & 0.5 & 0.4 & 0.4 & 44 & 640 \\
\hline $\mathrm{AC}$ & 1.3 & 1.1 & 1.4 & 1.3 & 1.5 & 1.6 & 1.5 & 1.5 & 16 & 500 \\
\hline FL & 7.0 & 7.4 & 13.0 & 6.3 & 8.7 & 10.3 & 6.3 & 10.9 & 19 & 540 \\
\hline PHE & 24.2 & 19.5 & 32.2 & 20.9 & 23.8 & 31.4 & 22.4 & 26.3 & 240 & 1500 \\
\hline $\mathrm{AN}$ & 1.3 & 1.0 & 2.2 & 1.1 & 1.3 & 1.1 & 1.1 & 0.9 & 853 & 1100 \\
\hline FA & 27.0 & 25.6 & 91.9 & 34.8 & 17.4 & 28.6 & 26.4 & 11.4 & 600 & 5100 \\
\hline PY & 19.1 & 18.3 & 56.9 & 22.9 & 11.3 & 19.0 & 17.5 & 8.5 & 665 & 2600 \\
\hline $\mathrm{BaA}$ & 6.3 & 5.5 & 13.0 & 6.5 & 4.3 & 3.6 & 4.5 & 2.6 & 261 & 1600 \\
\hline CHR & 13.8 & 12.3 & 31.8 & 16.0 & 9.8 & 8.4 & 10.5 & 14.7 & 384 & 2800 \\
\hline $\mathrm{BbFA}$ & n.d & n.d & n.d & n.d & n.d & n.d & n.d & n.d & n.a & n.a \\
\hline BkFA & 3.5 & 2.9 & 7.1 & 4.0 & 3.1 & 3.6 & 2.0 & 2.2 & n.a & NA \\
\hline $\mathrm{BaP}$ & 1.7 & 1.3 & 4.0 & 2.3 & 1.9 & 4.4 & 0.8 & 2.0 & 430 & 1600 \\
\hline IP & n.d & n.d & n.d & n.d & n.d & n.d & n.d & n.d & n.a & n.a \\
\hline DBahA & n.d & n.d & n.d & n.d & n.d & n.d & n.d & n.d & 63.4 & 260 \\
\hline BghiP & 1.8 & 1.6 & 6.4 & 1.8 & 1.5 & 5.1 & 1.3 & 1.1 & n.a & n.a \\
\hline$\sum 16$ PAHs & 163.7 & 103.3 & 261.7 & 169.0 & 92.0 & 123.0 & 150.6 & 83.2 & 4000 & 44792 \\
\hline
\end{tabular}

162 n.d: not detected; n.a: not available; ERL: effects range low; ERM: effects range median (Gu et al. 2013).

\subsection{Composition profiles of PAHs}

Fig. 3 shows composition pattern of PAHs by ring size in the surface sediments

166 from Fuxian Lake. Four-ring PAHs (39.1-73.9\%) were most abundant in all samples,

167 followed by three-ring PAHs ranging from 17.8 to $48.2 \%$, except in samples from F1,

$168 \mathrm{~F} 4$ and F7, where the two-ring PAHs ranked second at 34.3, 29.9 and $37.1 \%$,

169 respectively. The composition pattern of PAHs was usually characterized by the

170 dominance of high molecular weight (HMW, 4-6 benzenoid rings) PAHs. In a similar

171 study on surface sediments from lacustrine environment, Zhao et al. (2014) also found

172 higher concentrations of HMW PAHs than of low molecular weight (LMW, 2-3

173 benzenoid rings) PAHs. FA and PHE were the most dominant components in the

174 sediment samples studied, accounting for $13.7-35.1 \%$ (mean $21.3 \%$ ) and $12.3-31.7 \%$ 

PAHs.

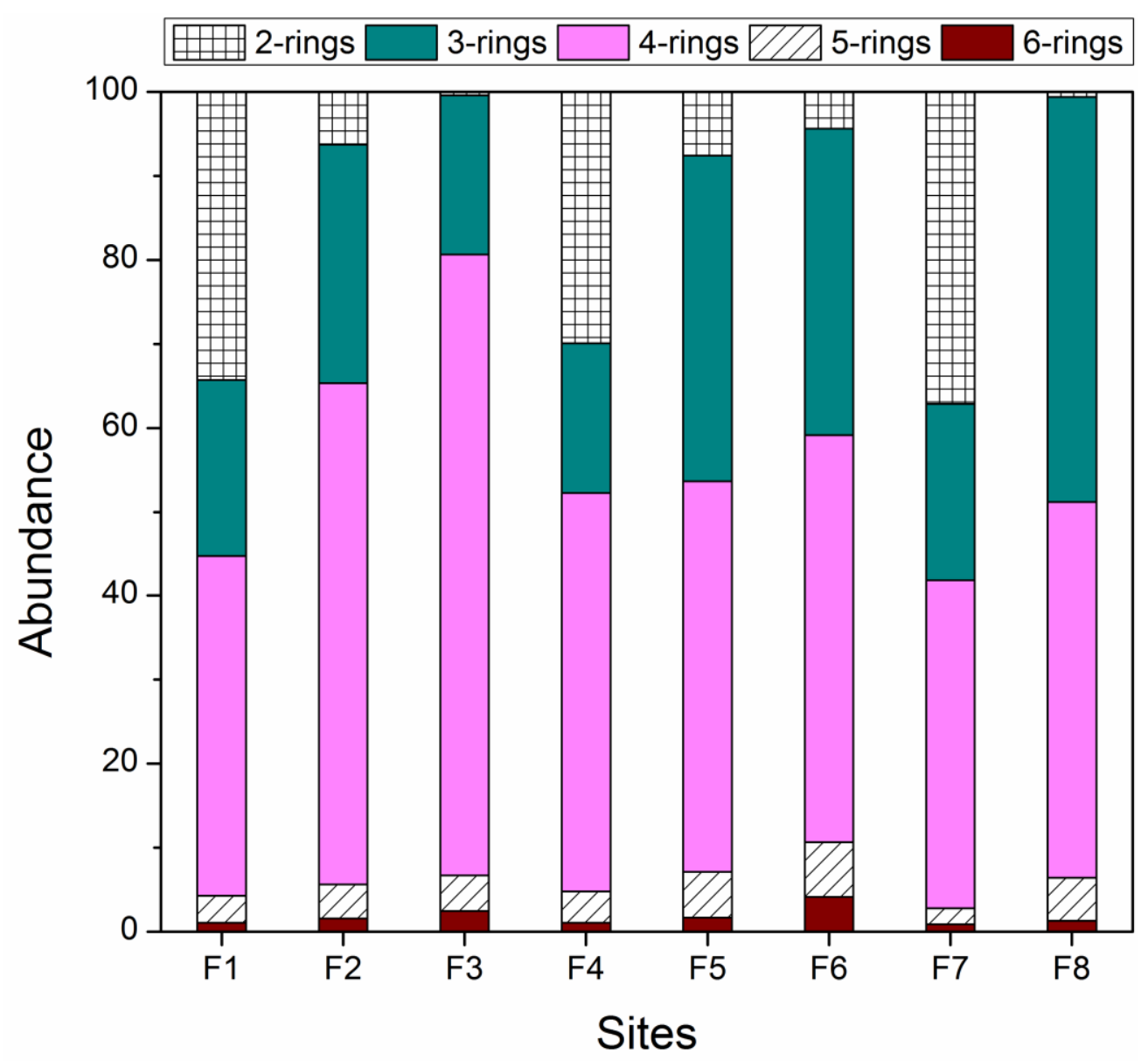

\subsection{Relationship between sediment characteristics and PAHs}

Several studies have shown that TOC and grain size are two important controlling 
186

187

188

189

190

191

192

193

194

195

196

197

198

199

200

201

grain size. In our study, TOC was positively significantly correlated with total PAHs, AN, FA, PY and BaA. In contrast, there were no significant correlation between percentages of sand, silt, and clay and total as well as individual PAH concentrations, suggesting that grain size is only a minor factor influencing PAH accumulation. Our results are in agreement with the findings by Timoney and Lee (2011), who did not observe a correlation between PAH concentration and sediment grain size.

\subsection{Source identification of PAHs}

PAHs of anthropogenic origin have various sources, including biomass and fossil fuel combustion and oil spills (Guo and others 2010). Diagnostic concentration fractions of PAH isomers are often applied to identify potential sources of PAHs (Yunker and others 2002; Yang and others 2016). In the present work, the molecular diagnostic ratios of $\mathrm{FA} /(\mathrm{FA}+\mathrm{PY})$ and $\mathrm{BaA} /(\mathrm{BaA}+\mathrm{CHR})$ were used for this identification, and the results are schematically shown in Fig. 4. According to the source classification by Yunker et al. (2002), of the PAHs in the sediments mainly originate from biomass, coal combustion, and petroleum combustion. 


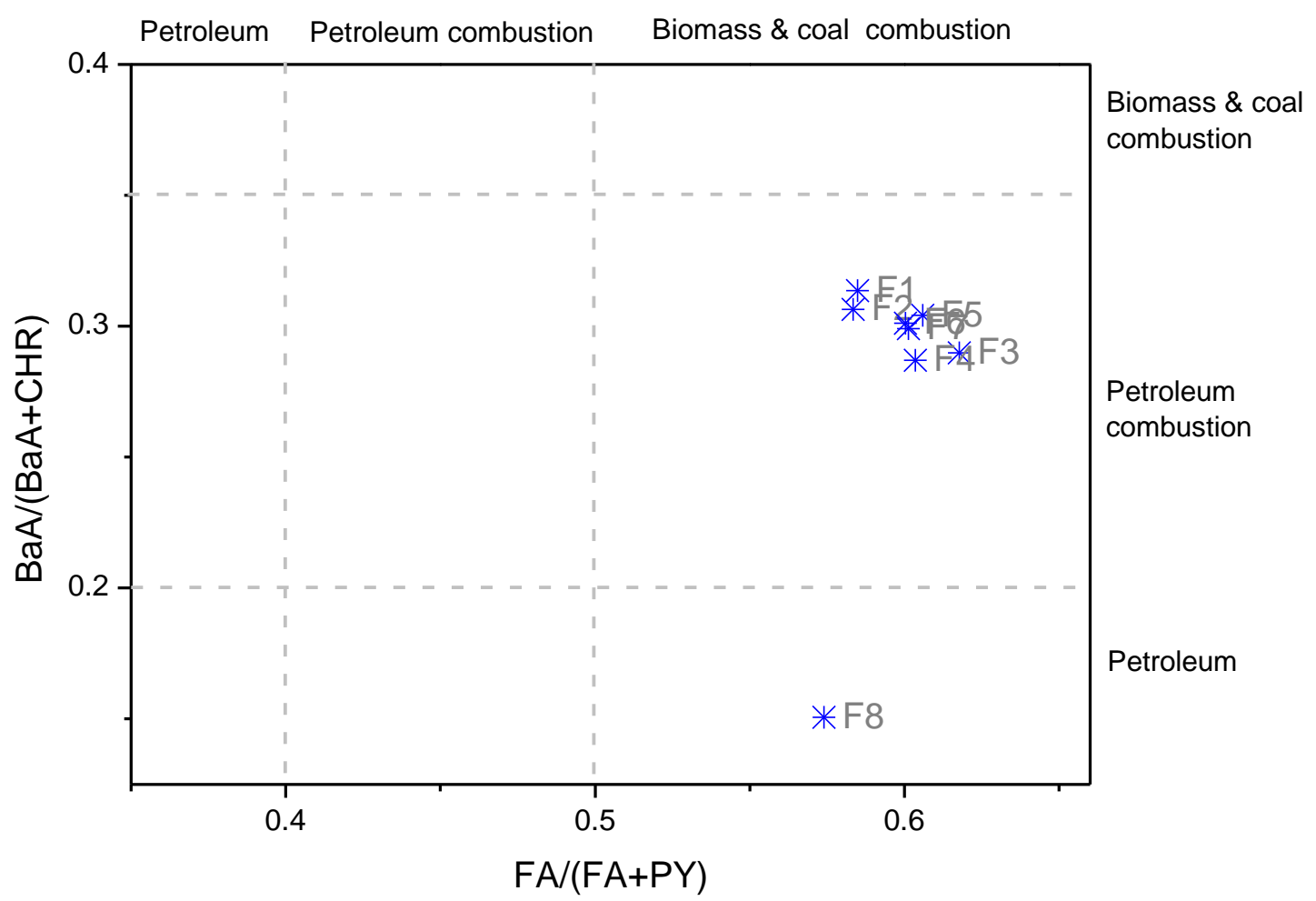

Fig. 4. Bivariate plot of PAH diagnostic ratios in lake sediments. PAH sources identification by Yunker et al. (Yunker and others 2002): FA/(FA+PY) < 0.4: petroleum, $0.4<\mathrm{FA} /(\mathrm{FA}+\mathrm{PY})<0.5$ :petroleum combustion, $\mathrm{FA} /(\mathrm{FA}+\mathrm{PY})>0.5$ : biomass and coal combustion; $\mathrm{BaA} /(\mathrm{BaA}+\mathrm{CHR})<0.2$ : petroleum, $0.2<\mathrm{BaA} /(\mathrm{BaA}+\mathrm{CHR})<$ 0.35: petroleum combustion, $\mathrm{BaA} /(\mathrm{BaA}+\mathrm{CHR})>0.35$ : biomass and coal combustion.

\subsection{Biological risk assessment}

Effects range-low (ERL) and effects range-median (ERM), depending on numerous toxicity tests, field studies, and altered benthic communities are the main parameters to evaluate the adverse biological effects of PAHs in marine and estuary sediments (Long and others 1995). As shown in Table 1, the concentrations of total and individual PAHs at all sites were below the ERL values, indicating that adverse effects on benthic organisms are rare.

As PAHs in sediments usually occur as mixtures, the mean ERM quotient method was proposed as a way to determine the possible biological effect of combined toxicant groups by computing mean quotients for a large range of contaminants 
including PAHs (Carr and others 1996; Long 2006); it can be calculated using the formula:

$$
\text { mean ERM quotient }=\sum\left(\mathrm{C}_{\mathrm{x}} / \mathrm{ERM}_{\mathrm{x}}\right) / \mathrm{n} \text {, }
$$

222 where $\mathrm{C}_{\mathrm{x}}$ is the measured concentration of the examined component ( $\mathrm{x}$ ) in sediments, $223 \mathrm{ERM}_{\mathrm{x}}$ is the ERM for PAH $\mathrm{x}$, and $\mathrm{n}$ is the number of PAHs. According to the mean 224 ERM quotient method by Long et al. (2000), mean ERM quotients below 0.11 have a $2259 \%$ probability of being toxic, quotients of $0.11-0.5$ have a $21 \%$ probability, quotients of 0.51-1.5 have a $49 \%$ probability, and quotients greater than 1.50 have a $76 \%$ probability. In surface sediments of Fuxian Lake, the mean ERM quotients were below 0.11 , indicating that the combination of the studied PAHs has a $9 \%$ probability of being toxic (Fig. 5).

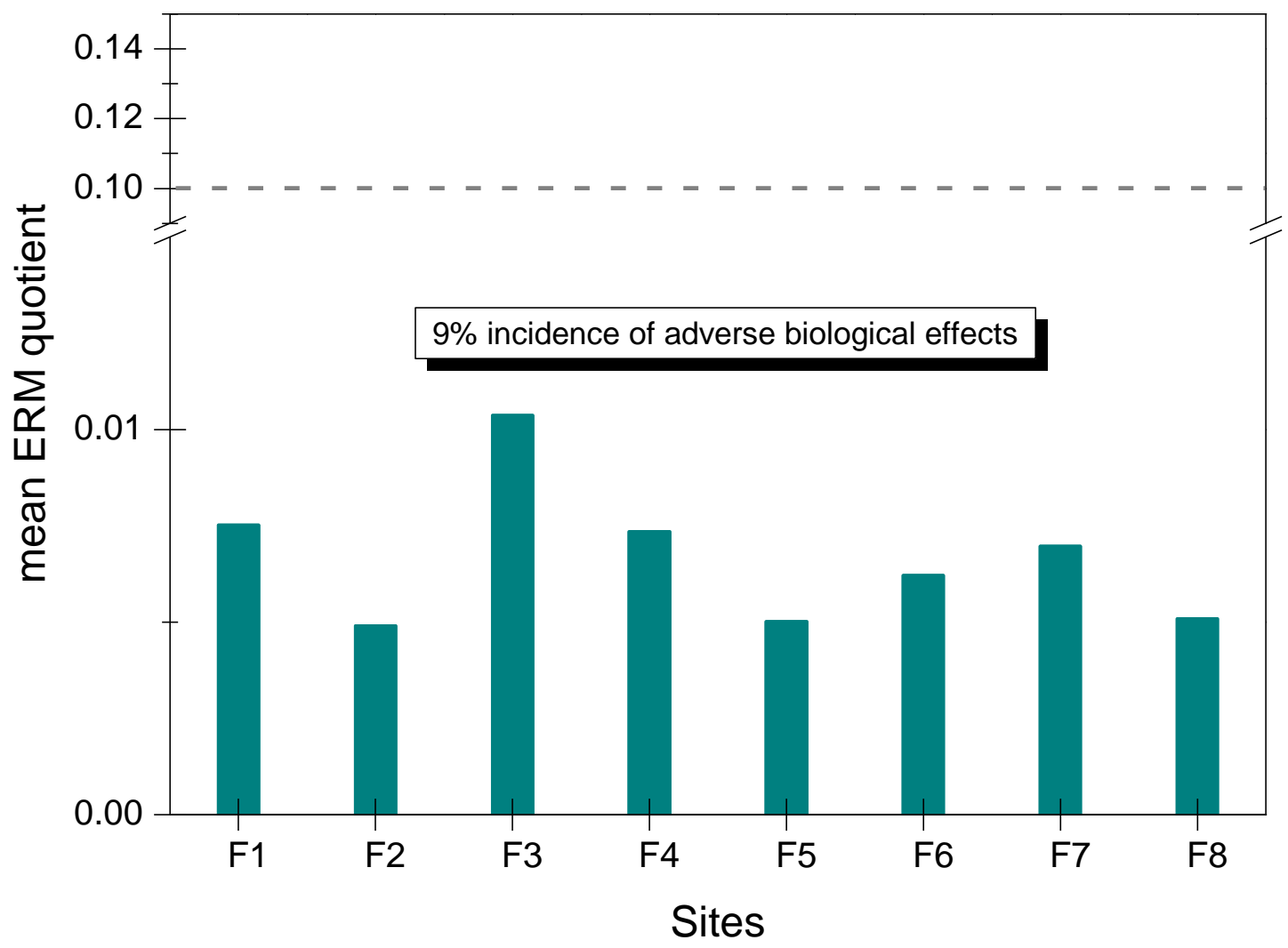




\section{Conclusions}

Total PAH concentrations in surface sediments of Fuxian Lake, the largest deep

235 plateau lake in China, were in the range of 83.2 to $261.7 \mathrm{ng} / \mathrm{g}$. FA was the most

236 abundant PAH, followed by PHE, NA and PY; together, these four PAHs contributed

237 more than $71.6 \%$ to the total PAH concentration. Bap, which has the highest

238 carcinogenic potential, was detected at all sampling sites. The PAH composition

239 pattern was usually characterized by the dominance of high molecular weight PAHs.

240 We found a significant correlation between total PAH concentrations and TOC levels,

241 indicating that TOC is a key property for PAH accumulation in these sediments. PAH

242 diagnostic ratios indicated that PAHs mainly derived from biomass, coal, and

243 petroleum combustion. The concentrations of total and individual PAHs at all sites

244 were below the ERL values, indicating that adverse effects on benthic organisms are 245 unlikely.

U1202231). 


\section{References:}

Agarwal, T.; Bucheli, T.D. Is black carbon a better predictor of polycyclic aromatic hydrocarbon distribution in soils than total organic carbon? Environmental Pollution. 159:64-70; 2011

Boström, C.-E.; Gerde, P.; Hanberg, A.; Jernström, B.; Johansson, C.; Kyrklund, T.; Rannug, A.; Törnqvist, M.; Victorin, K.; Westerholm, R. Cancer risk assessment, indicators, and guidelines for polycyclic aromatic hydrocarbons in the ambient air. Environmental Health Perspectives. 110:451-488; 2002

Carr, S.R.; Chapman, D.C.; Long, E.R.; Windom, H.L.; Thursby, G.; Sloane, G.M.; Wolfe, D.A. Sediment quality assessment studies of Tampa bay, Florida. Environmental Toxicology and Chemistry. 15:1218-1231; 1996

De Jonge, M.; Teuchies, J.; Meire, P.; Blust, R.; Bervoets, L. The impact of increased oxygen conditions on metal-contaminated sediments part I: Effects on redox status, sediment geochemistry and metal bioavailability. Water Research. $46: 2205-2214 ; 2012$

Gregg, T.; Prahl, F.G.; Simoneit, B.R.T. Suspended particulate matter transport of polycyclic aromatic hydrocarbons in the lower Columbia River and its estuary. Limnology and Oceanography. 60:1935-1949; 2015

Gu, Y.G.; Ke, C.L.; Liu, Q.; Lin, Q. Polycyclic aromatic hydrocarbons (PAHs) in sediments of Zhelin Bay, the largest mariculture base on the eastern Guangdong coast, South China: Characterization and risk implications. Marine Pollution Bulletin. 110:603-608; 2016 
Gu, Y.G.; Lin, Q.; Lu, T.T.; Ke, C.L.; Sun, R.X.; Du, F.Y. Levels, composition profiles and sources of polycyclic aromatic hydrocarbons in surface sediments from Nan'ao Island, a representative mariculture base in South China. Marine Pollution Bulletin. 75:310-316; 2013

Guo, J.Y.; Wu, F.C.; Luo, X.J.; Liang, Z.; Liao, H.Q.; Zhang, R.Y.; Li, W.; Zhao, X.L.; Chen, S.J.; Mai, B.X. Anthropogenic input of polycyclic aromatic hydrocarbons into five lakes in Western China. Environmental Pollution. $158: 2175-2180 ; 2010$

Heiri, O.; Lotter, A.; Lemcke, G. Loss on ignition as a method for estimating organic and carbonate content in sediments: reproducibility and comparability of results. Journal of Paleolimnology. 25:101-110; 2001

Hu, G.C.; Luo, X.J.; Li, F.C.; Dai, J.Y.; Guo, J.Y.; Chen, S.J.; Hong, C.; Mai, B.X.; Xu, M.Q. Organochlorine compounds and polycyclic aromatic hydrocarbons in surface sediment from Baiyangdian Lake, North China: Concentrations, sources profiles and potential risk. Journal of Environmental Sciences. $22: 176-183 ; 2010$

Li, B.H.; Feng, C.H.; Li, X.; Chen, Y.X.; Niu, J.F.; Shen, Z.Y. Spatial distribution and source apportionment of PAHs in surficial sediments of the Yangtze Estuary, China. Marine Pollution Bulletin. 64:636-643; 2012

Liu, G.M.; Liu, Z.W.; Li, Y.; Chen, F.Z.; Gu, B.H.; Smoak, J.M. Effects of fish introduction and eutrophication on the cladoceran community in Lake Fuxian, a deep oligotrophic lake in southwest China. Journal of Paleolimnology. 
Long, E.R. Calculation and uses of mean sediment quality guideline quotients: A critical review. Environmental Science \& Technology. 40:1726-1736; 2006

Long, E.R.; MacDonald, D.D.; Severn, C.G.; Hong, C.B. Classifying probabilities of acute toxicity in marine sediments with empirically derived sediment quality guidelines. Environmental Toxicology and Chemistry. 19:2598-2601; 2000

Long, E.R.; Macdonald, D.D.; Smith, S.L.; Calder, F.D. Incidence of adverse biological effects within ranges of chemical concentrations in marine and estuarine sediments. Environmental Management. 19:81-97; 1995

Lu, M.; Zeng, D.C.; Liao, Y.; Tong, B. Distribution and characterization of organochlorine pesticides and polycyclic aromatic hydrocarbons in surface sediment from Poyang Lake, China. Science of The Total Environment. 433:491-497; 2012

Martins, C.C.; Bícego, M.C.; Rose, N.L.; Taniguchi, S.; Lourenço, R.A.; Figueira, R.C.L.; Mahiques, M.M.; Montone, R.C. Historical record of polycyclic aromatic hydrocarbons (PAHs) and spheroidal carbonaceous particles (SCPs) in marine sediment cores from Admiralty Bay, King George Island, Antarctica. Environmental Pollution. 158:192-200; 2010

Mudroch, A.; Azcue, J.M. Manual of Aquatic Sediment Sampling: CRC Press; 1995

Perera, F.P. Environment and cancer: who are susceptible? Science. 278:1068-1073; 1997

San José, R.; Pérez, J.L.; Callén, M.S.; López, J.M.; Mastral, A. BaP (PAH) air quality 
modelling exercise over Zaragoza (Spain) using an adapted version of WRF-CMAQ model. Environmental Pollution. 183:151-181; 2013

Shen, H.Z.; Huang, Y.; Wang, R.; Zhu, D.; Li, W.; Shen, G.F.; Wang, B.; Zhang, Y.Y.; Chen, Y.C.; Lu, Y. Global atmospheric emissions of polycyclic aromatic hydrocarbons from 1960 to 2008 and future predictions. Environmental Science \& Technology. 47:6415-6424; 2013

Shepard, F.P. Nomenclature based on sand-silt-clay ratios. Journal of Sedimentary Research. 24:151-158; 1954

Timoney, K.P.; Lee, P. Polycyclic aromatic hydrocarbons increase in athabasca river delta sediment: Temporal trends and environmental correlates. Environmental Science \& Technology. 45:4278-4284; 2011

Wang, J.Z.; Zhang, K.; Liang, B.; Zeng, E.Y. Occurrence, source apportionment and toxicity assessment of polycyclic aromatic hydrocarbons in surface sediments of Chaohu, one of the most polluted lakes in China. Journal of Environmental Monitoring. 13:3336-3342; 2011

Wang, X.C.; Zhang, Y.X.; Chen, R.F. Distribution and partitioning of polycyclic aromatic hydrocarbons (PAHs) in different size fractions in sediments from Boston Harbor, United States. Marine Pollution Bulletin. 42:1139-1149; 2001

White, H.K.; Xu, L.; Eglinton, T.I.; Reddy, C.M. Abundance, composition, and vertical transport of PAHs in marsh sediments. Environmental Science \& Technology. 39:8273-8280; 2005

Yan, W.; Chi, J.S.; Wang, Z.Y.; Huang, W.X.; Zhang, G. Spatial and temporal 
distribution of polycyclic aromatic hydrocarbons (PAHs) in sediments from Daya Bay, South China. Environmental Pollution. 157:1823-1830; 2009

Yang, R.Q.; Xie, T.; Li, A.; Yang, H.D.; Turner, S.; Wu, G.J.; Jing, C.Y. Sedimentary records of polycyclic aromatic hydrocarbons (PAHs) in remote lakes across the Tibetan Plateau. Environmental Pollution. 214:1-7; 2016

Yunker, M.B.; Macdonald, R.W.; Vingarzan, R.; Mitchell, R.H.; Goyette, D.; Sylvestre, S. PAHs in the Fraser River basin: a critical appraisal of PAH ratios as indicators of PAH source and composition. Organic Geochemistry. $33: 489-515 ; 2002$

Zeng, H.A.; Wu, J.L. Sedimentary records of heavy metal pollution in Fuxian Lake, Yunnan Province, China: Intensity, history, and sources. Pedosphere. 19:562-569; 2009

Zhang, Y.; Guo, C.S.; Xu, J.; Tian, Y.Z.; Shi, G.L.; Feng, Y.C. Potential source contributions and risk assessment of PAHs in sediments from Taihu Lake, China: Comparison of three receptor models. Water Research. 46:3065-3073; 2012

Zhang, Y.D.; Su, Y.L.; Liu, Z.W.; Chen, X.C.; Yu, J.L.; Di, X.D.; Jin, M. Sediment lipid biomarkers record increased eutrophication in Lake Fuxian (China) during the past 150 years. Journal of Great Lakes Research. 41:30-40; 2015

Zhao, L.; Zhang, X.L.; Liu, Y.; He, B.; Zhu, X.; Zou, R.; Zhu, Y.G. Three-dimensional hydrodynamic and water quality model for TMDL development of Lake Fuxian, China. Journal of Environmental Sciences. 24:1355-1363; 2012 

X.J. Environmental behavior of PAHs in Dianchi Lake distributions, sources and risk assessment of polycyclic aromatic hydrocarbons in surface sediments from Dianchi Lake,China. International Journal of Environmental 


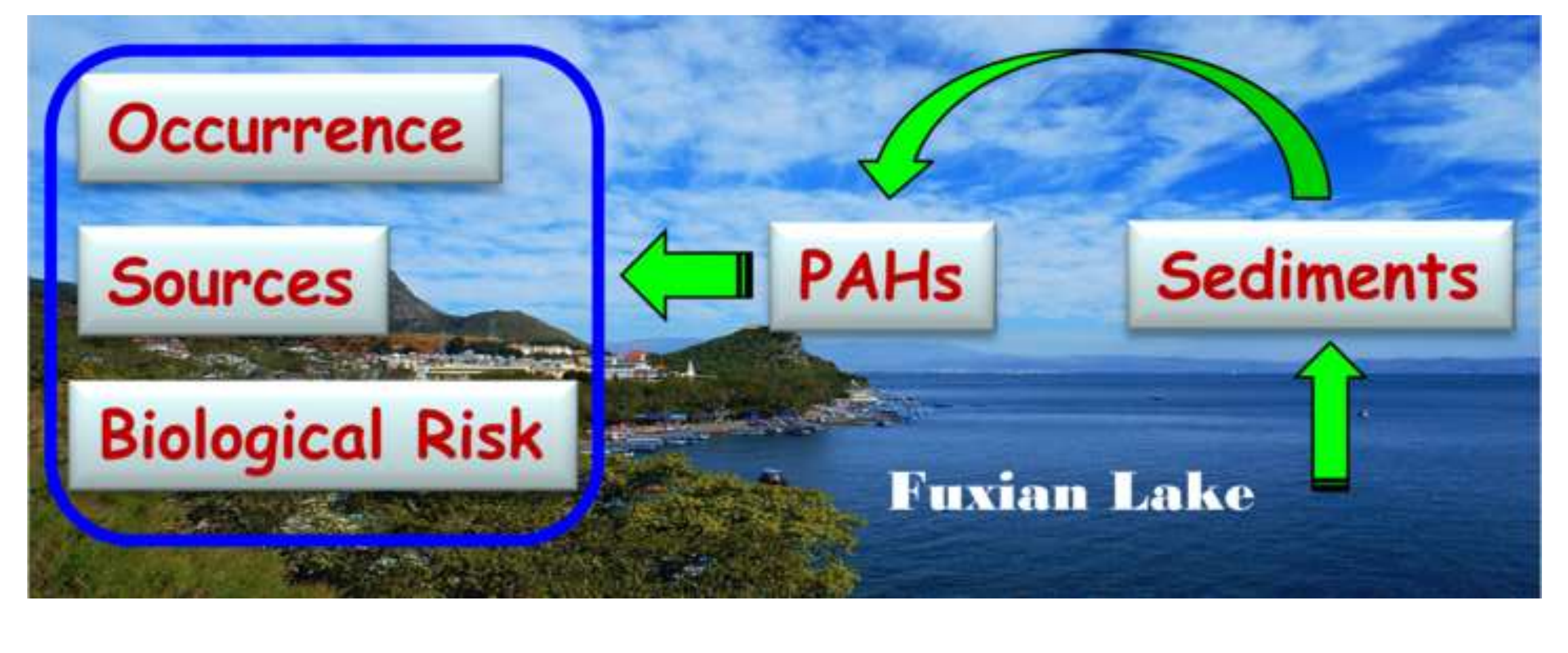

\section{Occurrence}

Biological Risk

\section{Fuxian Lake}

\section{Sediments}

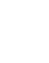

